\title{
ENDOSCOPIC MANAGEMENT OF UPPER URINARY TRACT UROTHELIAL MALIGNANCIES: BROADENING EXPERIENCE
}

\author{
Michael Grasso.
}

Department of Urology. Saint Vincent Medical Center New York. New York. USA.

Summary.- Upper urinary tract urothelial tumors reflect a small but growing number of urologic malignancies. The application of progressive endoscopic therapies including ureteroscopic and percutaneous nephroscopic resection and topical chemotherapy have found success, defined as the preservation of the renal unit without malignant progression, in those with low grade lesions. Careful and meticulous diagnostic endoscopy with tissue sampling and cytologic evaluation is key to directing treatment and counseling patients with regard to the risk of recurrence and progression. It is the population with a low grade lesion and negative cytology that are most commonly selected for endsoscopic resection. Those with high grade lesions who opt for endoscopic resection are counseled that this therapy is palliative and can often control local symptoms but is infrequently curative. Surveillance endoscopy post endoscopic resection and topical chemotherapy is essential. With growing surgical experience and improved instrumentation, the complications associated with these and other endoscopic procedures is acceptably low.

Keywords: Upper urinary tract. TCCa. Ureteroscopic therapies. Laser.

Resumen.- Los tumores uroteliales del aparato urinario superior representan un pequeño número, aunque creciente, dentro de los tumores urológicos. La aplicación de tratamientos endoscópicos progresivos incluyendo la resección por ureteroscopia - nefroscopia percutánea con aplicación de quimioterapia tópica han resultado exitosos en las lesiones de bajo grado, definiendo el éxito como la preservación de la unidad renal sin progresión del tumor maligno. El diagnóstico endoscópico meticuloso y cuidadoso, con evaluación de muestras de tejido y citología, es fundamental para dirigir el tratamiento y aconsejar a los pacientes en relación con el riesgo de recurrencia y progresión. La población con lesiones de bajo grado y citología negativa son los más frecuentemente seleccionados para la resección endoscópica. A aquellos pacientes con lesiones de alto grado que optan por la resección endoscópica se les debe transmitir que el tratamiento es paliativo y puede frecuentemente controlar los síntomas locales pero que rara vez es curativo. La endoscopia de vigilancia después de la resección y la quimioterapia tópica son esenciales. Con el aumento de la experiencia quirúrgica y la mejoría del instrumental, las complicaciones asociadas con estas y otros procedimientos endoscópicos es aceptablemente baja.

Palabras clave: Tracto urinario superior. Carcinoma urotelial. Tratamiento ureteroscópico. Láser. 


\section{INTRODUCTION}

Upper urinary tract urothelial malignancies account for $5-6 \%$ of urothelial tumors. This is a growing group based in part on success of local therapies for lower urinary tract transitional cell malignancies, where recurrence occurs above the bladder. Intrarenal and ureteral malignancies often present a surgical dilemma in that they are frequently multifocaland can require complex surgical treatment. Nephroureterectomy, long considered the treatment of choice, may confer unacceptable morbidity. As with solid renal malignancies, nephron sparing procedures are anattractive alternative especially in those with impaired renal function who would requiring lifelong hemodialysis after nephrouretrectomy. This is of particular concern in patients with a compromised contralateral kidney, a solitary kidney, or bilateral. Since this disease is most prevalent in the elderly, there is a general concern with progression to renal failure in this group after nephrectomy. Just as important is the fact that a growing cohort of individuals with renal pelvis or ureteral urothelial tumors, once treated successfully for a vilateral process, will go on to develop contralateral disease (1).

It has been our aim to develop and employ advanced endoscopic therapies to treat upper urinary tract urothelial malignancies in an attempt to preserve renal function, while also obtaining an acceptable oncologic result. We have tried to replicate therapies and sought the success obtained historically with contemporary transurethral procedures and topical therapies performed for lower urinary tract urothelial tumors. This includes ureteroscopic and percutaneous endoscopic tumor resection, laser ablation, as well as topical therapies post endoscopy to minimize recurrence.

\section{Diagnostic Ureteroscopy: An Essential First Step}

Initial diagnostic evaluation is one key to the overall success of treatment in patients with upper urinart tract
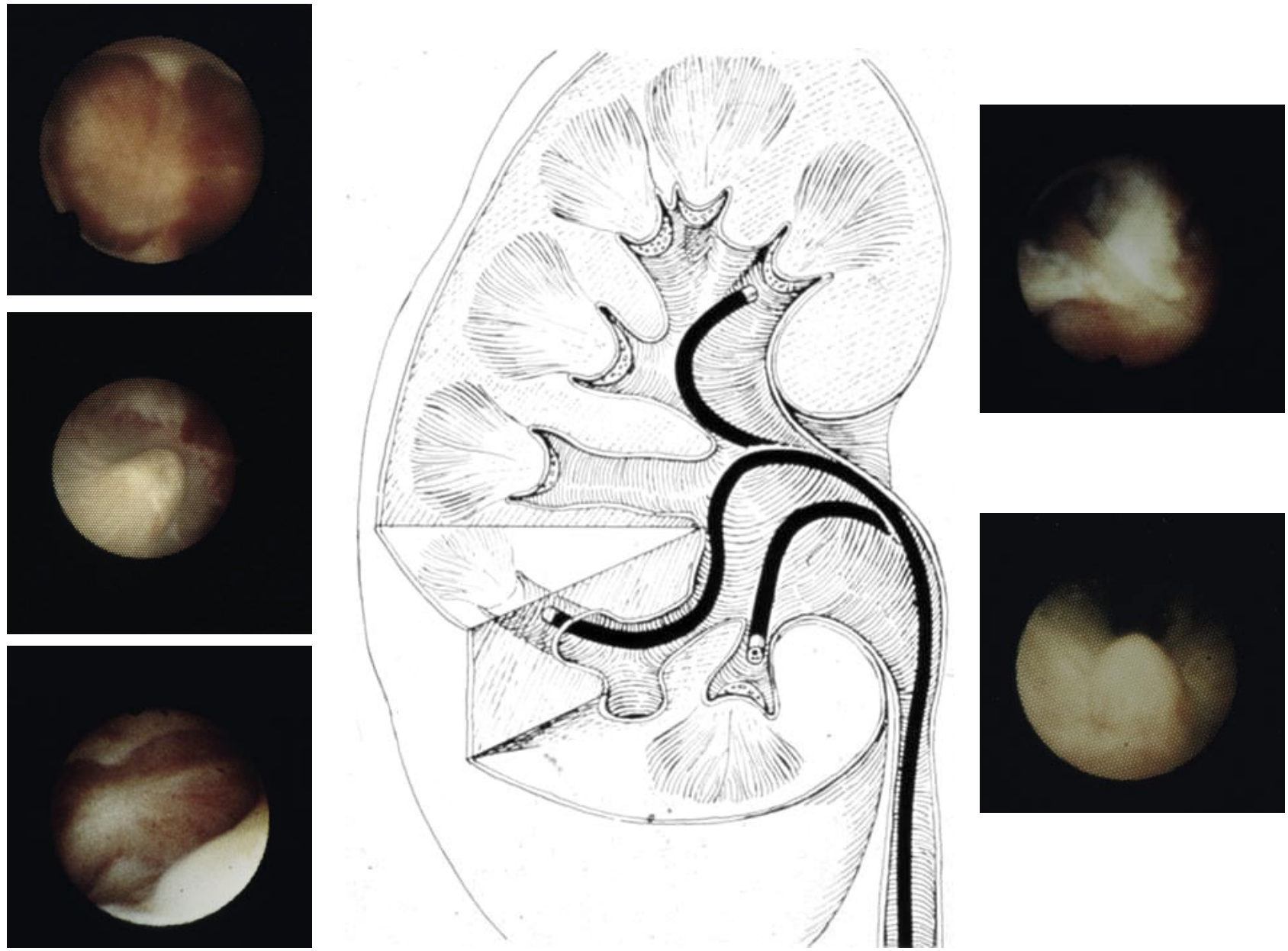

FIGURE 1. Flexible ureteroscopic mapping of the intra-renal collecting system employing a no touch ureteroscopic technique. Note that compound papilla are defined in the poles, while simple papilla are most common in the middle calyces. Occasionally a papilla without a calyx is noted, but is a rare finding. 
urothelial tumors. This includes CT or MR imaging of the retroperitoneum, urine tests including cytology and $\mathrm{FISH}$, and most importantly diagnostic ureteroscopy. Ureteroscopy is by far the most sensitive and accurate means of mapping upper tract urothelial tumors (2-5). Biopsy with either a basket/snare or cup biopsy forcept is essential. The results of these diagnostic tests will influence the ultimate crafting of a treatment plan $(5,6)$.

Diagnostic ureteroscopy begins with cystoscopic evaluation. Retrograde pyelography is then performed bilaterally Finally direct endoscoscopic inspection of the upper urinary tract is performed, employing technique that
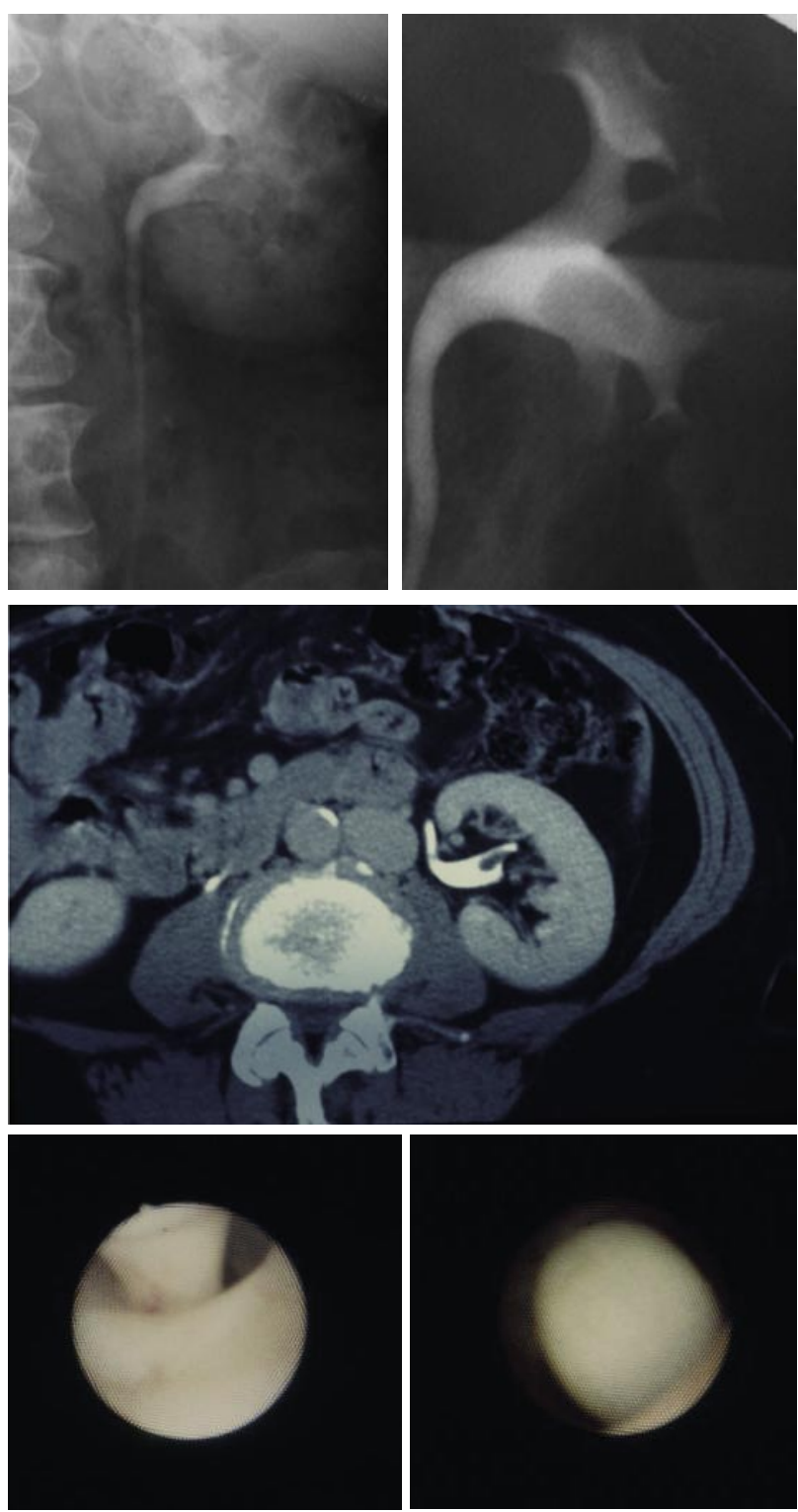

FIGURE 2. Benign lesions are differentiated from malignant tumors ureteroscopically. 2(a)Fibroepithelial Polyp. A filling defect is defined on intravenous pyelography, retrograde pyelogram, and CT imaging. Direct ureteroscopic inspection defined a pure white, soft lesions on a short stalk. minimaizes urothelial trauma to help prevent false positive results. Demetrius Bagley coined the term "No Touch" ureteroscopy in the early 1990's which refers to placing a ureteroscope directly into the upper urinary tract without a guidewire or sheath to facilitate complete urothelial inspection with minimal trauma from access devices. Initially this
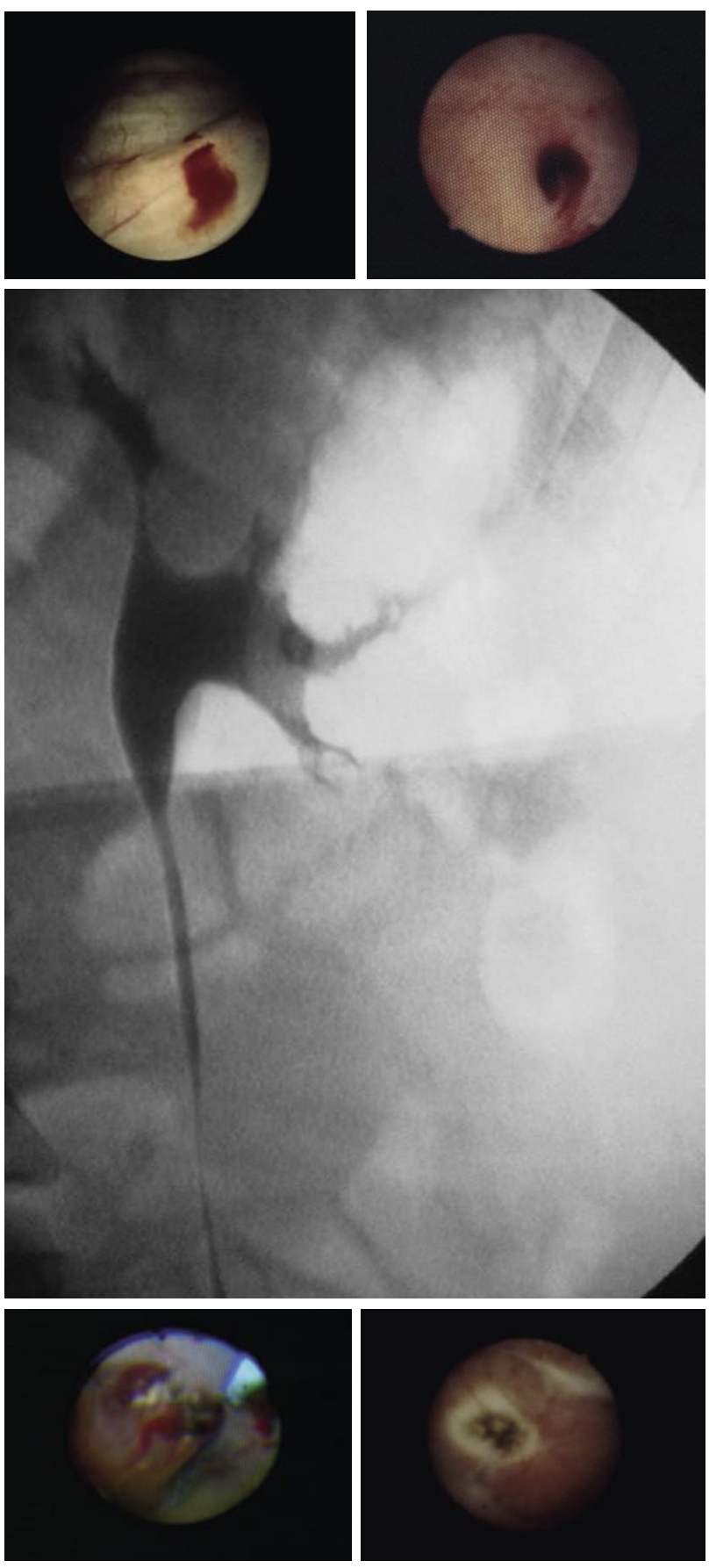

FIGURE 2B. Benign Essential Hematuria. Bloody efflux from a ureteral orifice does not always portend a malignancy. In these cases radiographic imaging is frequently not helpful,

with direct ureteroscopic inspection being diagnostic. A classic purple hemangioma is defined most commonly on a papilla, and bleeding can be stopped with electrocautery of laser energy. 
was performed with a small caliber semi-rigid employed for the distal ureter in men, and often the entire ureter in women (4-6). A guidewire was then place only to the level visualized with the rigid instrument and then over this wire an actively deflectable, flexible endoscope was passed, with subsequent complete stepwise inspection of the intrarenal collecting system and proximal ureter (Figure 1). The sensitivity of this technique rivals any other diagnostic modalities. In addition, improvements in flexible ureteroscope design since 2001 allow for complete inspection without a guidewire or ureteral dilation for access, often obviating the use of the semi-rigid endoscope (7).

Tissue sampling begins with a barbotage specimen of sterile saline obtained thru the working channel of the ureteroscope after mapping is complete (8). It is essential that the cytopathologist be familiar with the technique employed to obtain the specimen to help minimize false positives that reflect instrumentation artifact. If the endoscope mapping is complete and clear, a cytology report suggesting low grade urothelial disease is almost always a false positive reading reflecting either a thin film of normal urothelial cells rolled off with endoscope placement.

Based on the ureteroscopic mapping, a surgical treatment plan is crafted (Figure 2). Benign lesions must be differentiated from malignant. The variables which require careful consideration with regard to malignant lesions include tumor grade, volume, location, cytologic assessment, and the general comorbidities frequently found in this patient population (e.g. renal insufficiency, COPD, cardiac disease, etc). Most centers are offering ureteroscopic resection for low grade upper urinary tract lesions, similar to what is traditionally been performed in the bladder (9. 11). The diagnosis of low grade disease is based on both biopsy results and urine cytology obtained both from the upper urinary tract and the bladder $(5,8,12)$. Even if the ureteroscopic biopsies are consistent with a low grade process, positive class $V$ cytology infers a much higher grade process either reflecting incomplete sampling (i.e. low and high grade components) or concurrent carcinom in situ, both of which portend a poor outcome.

Most often the ureteroscopist can differentiate high and low grade lesions, as is commonly performed cystoscopically (Figure 3). Any lesions with a solid non-papillary component, or patches of beefy red mucosa suggesting carcinoma in situ, portend a higher grade process which infrequently can be cured with ureteroscopic treatment alone.

Papillary lesions are biopsied with either a flat wire stainless steel (i.e. Segura) or nitinol basket. Care must be taken when removing the specimen to preserve tissue architecture. With a papillary exophytic tumor, once engaged in the basket, the entire unit must be extracted together rather than removing the basket thru the endoscope working channel (Figure 4). This will increase the tissue yield and prevent sample disengagement from the basket wires cutting thru the sample.

Sampling of flat lesions is performed with 3 French cup biopsy forceps. Multiple samples extracted thru the working channel are required. The specimen are placed in a cylindrical tube filled with a small aliquot of saline which is delivered to a cytopatholgist who will employ a cell block technique on the pellet of spun down specimens as well as standard cytology of the supernatant. Trying to employ standard histopathologic preparation techniques with cassettes on these one millimeter or smaller fragments is unsatisfactory without special attention. Sampling a solid intrusive lesion, in comparison, can require either electrocautery or laser energy to excise a representative fragment which is then extracted and prepared with standard histopathologic technique.

Here again the importance of cytopatholgy cannot be overstated. Once a representative biopsy is perform, as long as the hematuria caused by this maneuver is not extreme, subsequent washings will increase the diagnostic yield.

Ureteroscopic biopsy specimens have been shown to correlate well with final pathologic specimens (12). Although ureteroscopy has not been demonstrated to be a dependable method of staging, the correlation between grade and stage is highly reliable (12-14). Low grade tumors are almost exclusively low stage.

\section{Endoscopic Therapy: Technical Issues}

In 1945 renal sparing surgery for upper tract urothelial tumors was first proposed by Vest (15). However, it was not until many years later inan effort to preserve renal function in patients with parenchymal disease that conservative treatment found acceptance. Conservative open
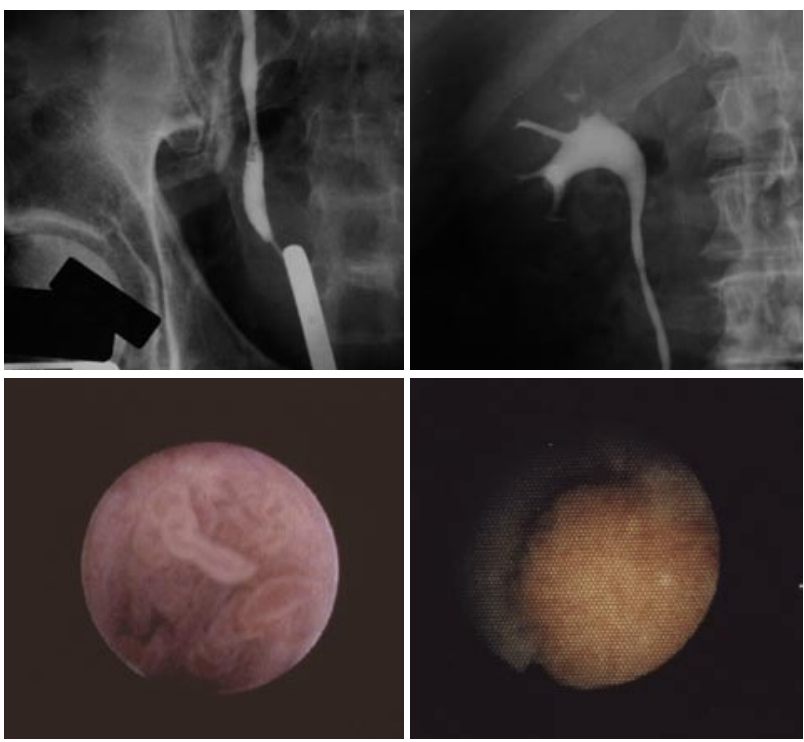

FIGURE 2C. Malignant urothelial lesions of the upper urinary tract have similar endoscopic features to lower urinary tract lesions. In this patient a retrograde pyelogram defines two lesions. An upper pole moderate grade infundibular tumor, and a circumferential low grade lesion in the distal ureter. 
therapy was reserved for individuals with solitary kidneys, compromised renal function or bilateral disease. As in the bladder, lower grade lesions are preferred when selecting patients for nephron sparing procedures (14).
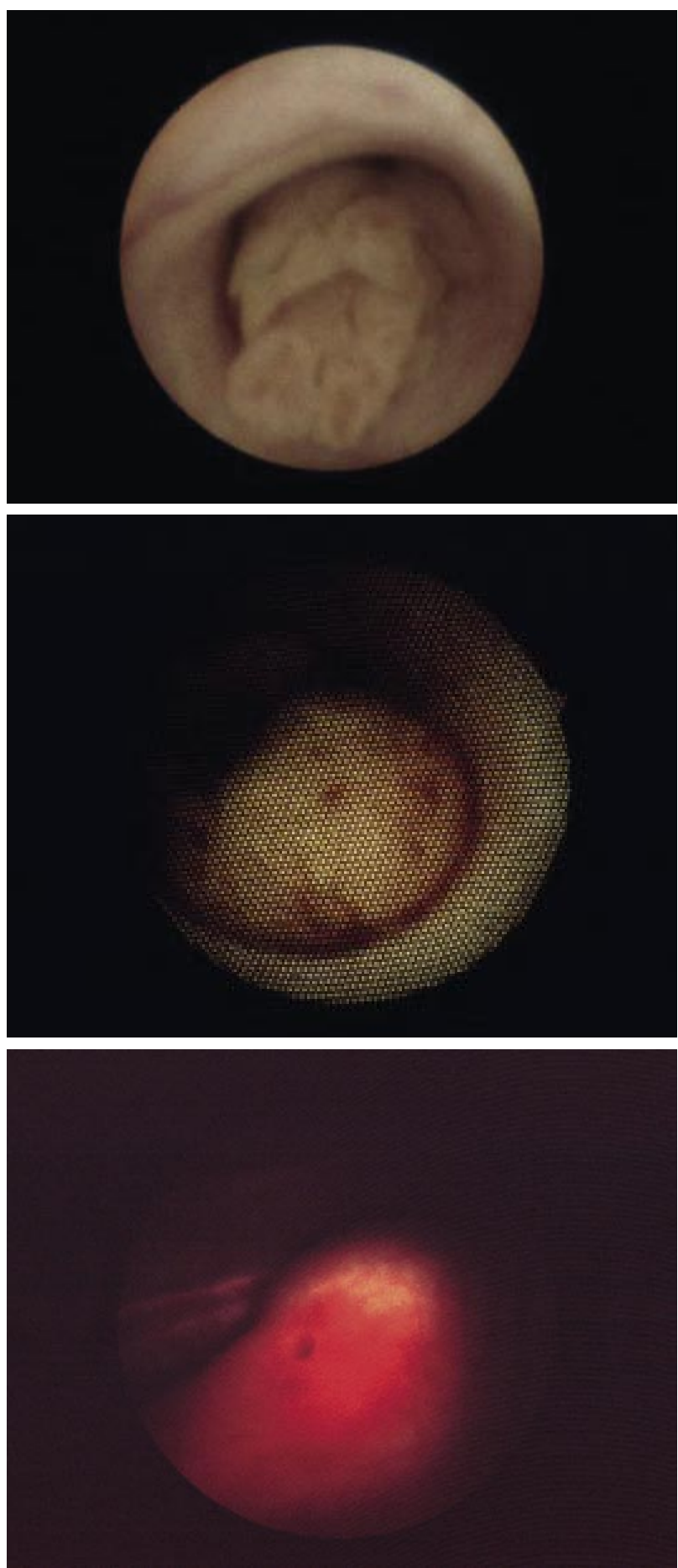

FIGURE 3. Differentiating malignant urothelial tumors ureteroscopically. Low grade lesions are papillary and are composed of bland cells with normal $\mathrm{n} / \mathrm{c}$ ratios. Higher grade lesions are either more solid appearing, or flat with erythema. In the last image, carcinoma in situ involves the ureteral orifice and distal ureter.
Percutaneous and ureteroscopic treatment of upper tract urothelial malignancies was first reported in the mid 1980's (16-18). Since these initial endoscopic therapies were first described, minimally invasive endoscopic techniques have progressed with the development of smaller and more steerable endoscopes. More than any other tool, the evolution of the actively deflectable, flexible endoscope has facilitated advances in the treatment of fumor in the upper ureter and renal collecting system.

Retrograde endoscopic treatment has also been furthered by the use of laser energy delivered thru flexible fiberoptic glass passed thru the working channels of these endoscopes. Both holmium and $\mathrm{Nd}$ :Yag lasers have been employed in this setting. Nd:YAG was employed first but was associated with higher stricture rates based in large part by the deep penetration noted with this wavelength (19). For example, with a setting of 60 watts employed on a tumor for a minute, the tissue coagulation depth will exceed on $\mathrm{cm}$. This deep thermal effect is difficult to control and frequently surrounding normal tissue is effected causing subsequent stricture. For these reasons this laser energy is employed at a lower power ( 30 watts) for short 15 second pulses to help minimize surrounding tissue destruction. $\mathrm{Nd}$ : YAG is useful at these setting for particularly vascular or large friable papillary tumors. Specifically, dual head solid state lasers which can deliver both $\mathrm{Nd}: \mathrm{YAG}$ and holmium are attractive in these settings $(4,5)$. Nd:YAG is employed first to coagulate papillary intraluminal tumor to minimize bleeding, then holmium laser energy can be employed to ablate or "resect" the pretreated areas. His technique can be repeated in a stepwise fashion to remove bulky lesions, with a dual footswitch being particularly useful to increase efficiency.

The holmium laser energy was first employed for tumor therapy to treat superficial bladder tumors (20). This laser energy has a high water affinity, creating a microscopic vaporization bubble at the tip of the delivering fiber which ablates stones, papillary tumors, and even dense fibrotic tissue. Holmium lasers energy is pulsed thru low water density quartz fibers, causing specific tissue effects based on the parameters chosen. By manipulating total energy and frequency of pulsation, a variety of tissue effects are noted. Low energy 10.6 joules and low frequency of pulsation 15 hertz) are common settings when treating papillary lesions in the bladder and upper urinary tract. By defocusing the laser energy at the fiber tip at a low power of 3-5 watts, papillary tumors are both coagulated and ablated. The pulsatile energy delivery visually appears to blow away and remove devascularized tumor, akin to endoscopic resection. Increasing the settings will change the effect with less coagulation. For example, to incise a stricture or cut a portion of solid tumor from the mass, energies of 1 to 1.4 joules and frequency of pulsation of 15 to 20 hertz are employed.

Electracautery continues to play a role in the ureteroscopic management of upper urinary tract urothelial tumors. Historically, 12 French ureteroresectoscopes were employed to resect distal ureteral tumors. These endoscopes, due to their large size, are infrequently employed. One exception is very large, low grade distal ureteral lesions. Commonly ureteral pre-stenting is required to facilitate en- 

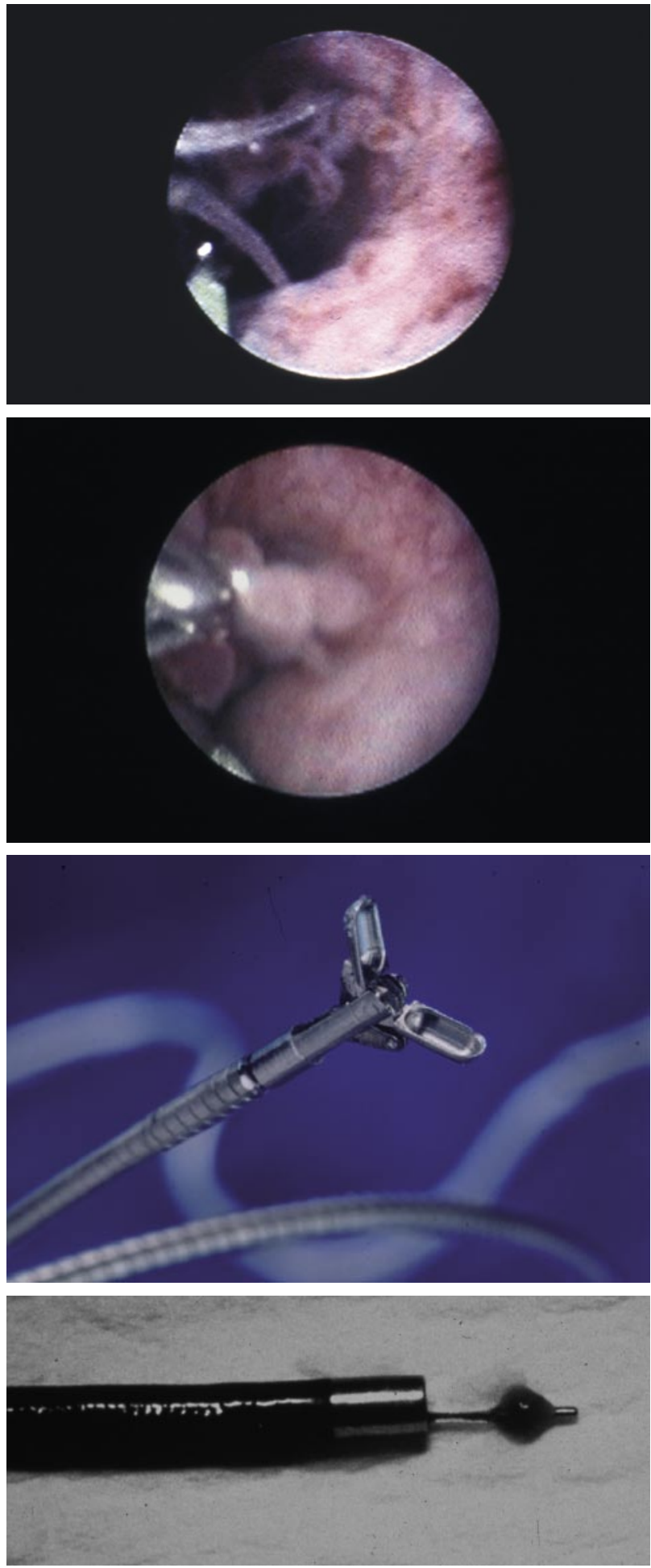

FIGURE 4. Ureteroscopic Biopsy Techniques. Baskets and snares are placed ureteroscopically adjacent to papillary urothelial tumors. The best yield is obtained by removing the endoscope and basket from the ureter as a common unit. Conversely, cup forceps are employed to biopsy flat or solid lesions. As compared to the basket technique, this device is placed repetitively thru the working channel of the endoscope, with all the one millimeter fragments combined in a cylindrical specimen tube for cell block cytopathologic evaluation. doscope placement. The other more common application of electrocautery the upper urinary tract is to treat lower pole lesions. The $2 \mathrm{~F}$ bugbee electrode does not inhibit flexible ureteroscope deflection and can be place more easily into a dependant lower pole calyx. The settings vary by cautery box manufacturer, but for practical purposes the cut and coagulation levels should be set as low as possible to obtain the desired tissue effect. Irrigant must also be adjusted when electrocautery is employed. Instead of standard sterile saline, sorbitol or small aliquots of sterile water are used. When sterile water is employed, careful attention to volume instilled, most often less than 200 cc's, is essential even with the undestaning that most of this fluid drains around the endoscope into the bladder.

When performing ureteroscopic treatment of upper urinary tract urothelial tumors, the endoscopist should employ various energy sources to clear all visible tumor (5). Commonly, different energy sources are interchanged to obtain desired effects based on the vascularity of the tumor and its location. Staged therapy is common, particularly when attempting to clear a large lesion shortly after primary diagnosis. Patients with circumferential ureteral tumors also are better served with sequential sessions after a period of healing. Ablative or coagulating energy is never applied circumferentially to the ureteral lumen at the same sitting, rather only segments of ureteral wall are treated with intervals of healing to help minimize ureteral stricture.

Percutaneous endoscopic tumor resection is employed for large intrarenal lesions or those that cannot be managed ureteroscopically for technical reasons $(21,22)$. For the facile ureteroscopist this is a very select group. These include patients with excessively long or tortuous ureters, and patients with urinary diversions where retrograde ureterosocpic access is difficult or prohibited. The violation of the urothelium with a percutaneous puncture has at least a theoretical risk of tumor seeding, even though in relatively large series this has been only noted rarely $(23,24)$. Treatment technique is similar to bladder therapies with the caveat that the upper urinary tract is composed of thinner walled structures overlying large vascular structures. Endoscopic resection similar to TURBT should not be performed percutaneously in the intrarenal collecting system. Most techniques are based on mechanical tumor debulking with laser and electracutery employed for the remainder either thru a flexible or rigid nephroscope. As opposed to stone management, a nephrostomy should be place post procedurally and only removed after a period which allows for tract maturation.

\section{Endoscopic Therapy: Post Procedure Topical Therapies}

As with bladder tumors, it is intuitiveto hope that topical therapies placed directly on the urothelium will positively affect outcomes. Low patient accrual and nonuniformity of this varied group has prohibited definitive statements. It is clear, however, that agents like BCG and Mitomycin affect urothelialtumor recurrence rates positively (25-27). The issue is whether the entire upper urinary tract is appropriately coated with these agents long enough. Placing agents in the bladder and hoping they will reflux up an internal double pigtail stent is more wishful than practical. 
The only sure means of administering these agents onto the urothelium of concern is to place a catheter directly into the upper tract in either a retrograde or percutaneous fashion for delivery (25).

Our center is not employing topical agent after endoscopic therapy for low volume, low grade lesions. Specifically, this treatment is employed in higher risk patients or in those who are having frequent recurrence. The technique employed after endoscopic therapy is based on placing a single pigtail, externally draining ureteralstent which is secured to a bladder drainage catheter. Correct catheter position is verified with contrast and fluoroscopy. In the recovery room, immediately after ureteroscopic therapy, 20 to $40 \mathrm{mg}$ of Mitomycin- $C$ in 50 to $100 \mathrm{cc}$ 's of diluentis delivered over 1 to 2 hours while the foley catheter is clamped. The dose, diluent volume, instillation time, and foley clamp time are adjusted based on the estimated volume of the upper urinary tract, with larger collecting systems requiring greater dose and volume. During the session patient complaint of pain, fever is noted, or any other negative clinical parameter leads to prompt cessation with drainage of both catheters.

Agents employed for topical therapy in the upper urinary tract include Mitomycin-C, BCG, Alpha interferon, and adriamycin. Of all these agents, Mitomycin-C has the lowest risk profile. Keeley found in his series that the risks were acceptable when the aforementioned technique was employed (27). He however could not validate this technique to statistical significance due to the small study size, but his results were encouraging. Martinez-Pineiro's group presented their experience with all four agents and found the best success with Mitomycin-C and BCG (9). The fundamental question is safety with delivery. Even though BCG has been employed at select centers after percutaneousnephroscopic tumor debulking, there have been cases, all be it rare, of high fevers and presumed bacillemia after this treatment. For this reason Mitomycin is our preferred agent $(28,29)$.

\section{Endoscopic Therapy: Indications, Outcomes, and Survei- llance Protocols}

With the advancement in minimally invasive treatment and recognition of the low metastatic potential of low grade lesions, the need for nephroureterectomy in individuals with low grade disease and two normal functioning kidneys has been questioned $(10,14,30-33)$. Retrograde endoscopic management of upper tract urothelial malignancies offers the advantage of preserving renal function and may also be performed on patients who would not tolerate more invasive therapeutic modalities. Morbidity is generally less with retrograde endoscopic procedures whichcan be performed on an out patient basis. Fundamental questions of efficacy and safety are balanced with the desire to preserve renal function and to avoid dialysis. As in the bladder, it is clear that those patients with low grade, low stage disease and negative washings of malignant cells which portends a low grade processes frequently achieve an acceptable oncologic outcome. Their risk of progression in grade and stage is low, but far from zero. In our data base, and the Mayo clinic experience, results have been were encouraging $(10,33)$. As follow-up increased to ten years out we are seeing more patients progress in grade, and then stage $115 \%$ of the patient population currently in surveillance post endoscopic therapy - Table I). This is not
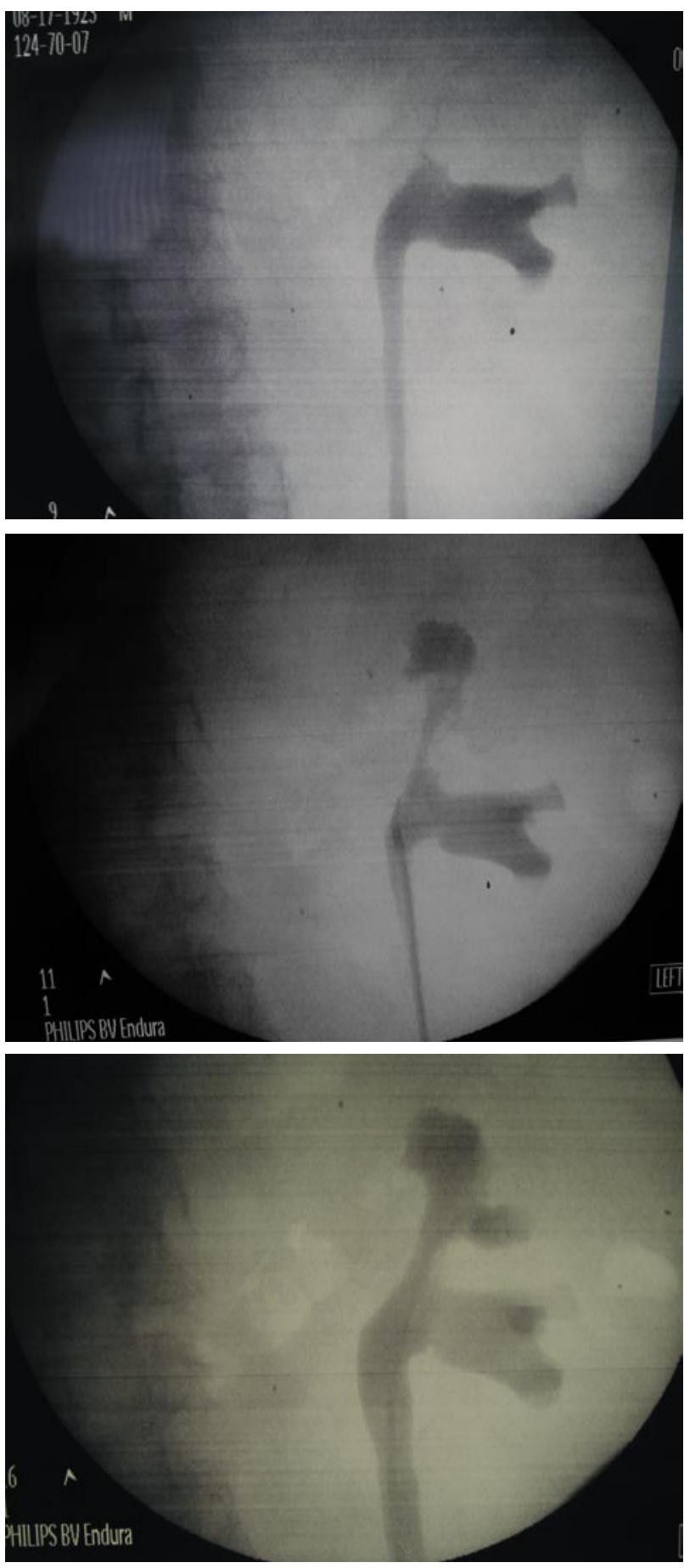

FIGURE 5. Staged Ureteropyeloscopic Treatment Of Upper Urinary Tract Transitional Cell Carcinoma. A large upper pole infundibular tumor is treated in three stages ureteroscopically. Combined electracautery and laser energy is placed on viable, vascular tumor. After a few weeks of tumor slough a second stage is performed. The last image reflects retrograde pyelography four weeks later and defines a smooth collecting system where all visible tumor had been resected. 
completely unexpected, when compared to results obtained post endoscopic resection of low grade bladder tumors. In this same population of patients with low grade tumors upper urinary tract urothelial tumors treated with ureteroscopic resection, low grade recurrence was common (67\%), with recurrence at the same site occurring much less frequently $(18 \%)$. These lesions are most often small and easily treated during surveillance.

Iborra et. al. has shown that previous multi-recurent bladder tumors and tumors in the renal pelvis are the

TABLE I. UPDATED DATABASE OF PATIENTS TREATED IN NEW YORK WITH LOW GRADE UPPER URINARY TRACT TRANSITIONAL CELL CARCINOMA WHO UNDERWENT URETEROSCOPIC THERAPY AND SURVEILLANCE PROTOCOL.

\begin{tabular}{|l|l|}
\hline & Low grade tumor \\
\hline Total patients & 45 \\
\hline Mean follow up & 37 (3-103 months) \\
\hline Mean tumor burden & $2.4 \mathrm{~cm}(0.5-10)$ \\
\hline Recurrent low grade disease & 31 (69\%) \\
\hline Mean time to first recurrence & 18.3 months (3-72) \\
\hline Recurrence at original site & $8(18 \%)$ \\
\hline Concurrent bladder cancer & $29(64 \%)$ \\
\hline Bilateral disease & $14(31 \%)$ \\
\hline Solitary kidneys & $12(27 \%)$ \\
\hline Progression in grade & $7(15 \%)$ \\
Within First 6 Months & $2 / 7$ \\
Grade and Stage & $4 / 7$ \\
(all higher grade when \\
progressed)
\end{tabular}

Note the progression rate in tumor grade is $15 \%$ with a maximum of 105 months follow-up. Two of the seven patients progressed early, within 6 months of diagnosis, and may have reflected under grading at the time of the initial biopsy. The others progressed much later, the maximum being over eight years from diagnosis of upper tract disease and over twenty years from the diagnosis of bladder carcinoma. strongest risk factors for recurrence and progressionof upper urinary tract tumors (14). These were also found to be the strongest risk factors for bilateral disease. Primary tumor size also appears to influence recurrence rate as Keeley et al reported that only $21 \%$ of patients with tumors $>1.5 \mathrm{~cm}$ were eventually rendered tumor free (11). We have also found that those presenting with tumors greater than 1.5 $\mathrm{cm}$ had a higher incidence of recurrence and did recur sooner. In our series, with vigorous treatment often in stages, we have cleaned large tumors up to $10 \mathrm{~cm}$. This is tedious and time consuming, requiring patience and persistence, but can be ultimately fruifful (Figure 5).

Patients with high grade upper tract urothelial lesions, including those with low grade lesions and positive cytology and those with a component of carcinoma in situ, frequently progress in stage after treatment. This includes patients treated ureteroscopically and those treated with radical nephrovereterectomy. In select patients with high grade disease we have offered ureteroscopic therapy, with many obtaining local control with resolution of symptoms. These patients are clearly counseled that this therapy is palliative. These patients tend to be older, higher risk for large surgical procedures, frequently with a component of renal insufficiency. It is our intent in this group to maintain renal function off dialysis by controlling local disease, but the progression to metastatic disease is high.

All patients who undergo either ureteroscopic or percutaneous endoscopic tumor therapy are clearly counseled that lifelong endoscopic surveillance is an essential part of the protocol and must consent to this before treatment is initiated. The standard protocol after complete tumor resection is to see patient back three months later for diagnostic ureteroscopy. If the endoscopic inspection is clear and the washing negative, then repeat upper urinary tract inspection is performed every six months, while cystoscopy alone is performed at the three month interval in between. Broad metastatic evaluation, including $\mathrm{Ct}$ or $\mathrm{MR}$ imaging of the retroperitoneum, is performed first semiannually, and then annually as the evaluations remain acceptable. Positive findings may adjust the interval back to more frequent. As in bladder, a few small low grade tumors noted during surveillance with otherwise negative parameters does not necessarily alter the surveillance protocol.

\section{Endoscopic Therapy: Complications}

The complications of retrograde endoscopic therapyhave decreased with the improved instrumentation and refined technique (Table II).A higher incidence of ureteral stricture with the ureteroscopic application ofNd:YAG laser energy is well documented (19). Not surprisingly, we have noted a higher rate ofinfundibularstenosis when this frequency of laser light is employed. As a routine, we very rarely employ $\mathrm{Nd}: \mathrm{YG}$ in the ureter, and have segregated its application to large vascular intrarenal lesions. In comparison, the shallow penetration of the Ho:YAG laser decreases the potential for stricture formation and has become our energy source of choice for most lesions.

Potentially life threatening complications can arise from the administration of adjuvant chemotherapy agents 
and discretion is essential when giving retrograde intracavitary topical therapies. Care must be taken not to apply agents likemitomycinunder high pressure so as to avoid systemic absorption and potential agranulocytosis (9). Intracavitary bacillus Calmette-Guerin therapy (BCG) has been used as an adjuvant agent administered through a nephrostomy tube with fever and overwhelming sepsis as reported complications in this setting $(26,28,284)$. We have not used BCG as an adjuvant agent for upper tract urothelial tumors because of the above noted complications although retrograde application of BCG has been reported (25).

Tumor seeding of the nephrostomy tract after percutaneous treatment of upper tract urothelial tumors has been reported (23). In an effort to avoid tract seeding, routine prophylactic irradiation of the nephrostomy tract is carried out at some centers (24). Retrograde ureteroscopic treatment avoids the potential complications of nephrostomy tract seeding, as such is the preferred in all but select patients.

Careful life long follow-up is essential in the treatment of upper tract urothelial cancer. As with superficial bladder cancer, patients require long term follow-up due to the relatively high incidence of recurrence. In our series first recurrence was identified up 63 months after initial therapy. Imaging studies alone cannot be relied upon to identify new or recurrent lesions as it has been shown that up to $75 \%$ of tumors identified by ureteroscopy are not identified radiographically (11). In some patients ureteroscopic surveillance may be carried out in the office setting. Of course, careful cystoscopy must also be performed on these patients as approximately one half of individuals with upper tract tumors will go on to develop bladder lesions.

\section{CONCLUSIONS}

Retrograde ureteroscopic treatment of upper tract urothelial tumors is particularly useful in patients who present with low-grade lesions. Endoscopic management was once considered a therapy of last resort, reserved for those with a solitary kidney, renal insufficiency, or severe medical co-morbidities. The low rate of progression of tumor stage or grade in those patients with low grade primary lesions is encouraging, but lifelong surveillance is required for progression can occur. The low morbidity associated with ureteroscopic treatment of these tumors provides a reaso-

TABLE II. COMPARISON OF COMPIICATION RATES ASSOCIATED WITH URETEROSCOPY, EMPHASIZING THE NOTICEABLE DECREASE IN THE MAJOR COMPLICATION RATE WITH GREATER EXPERIENCE AND ENDOSCOPE MINIATURIZATION.

\begin{tabular}{|c|c|c|c|c|}
\hline Author & Blute, Mayo Clinic & Adlel-Razzak, Th. Jefferson & Harmon, Mayo Clinic & Grasso, NYU \\
\hline Year Published & 1988 & 1992 & 1997 & 2001 \\
\hline Procedures & 346 & 290 & 209 & 1000 \\
\hline \multicolumn{5}{|l|}{ Minor Complications, \% } \\
\hline Fever & 6.2 & 6.9 & 2 & 1.3 \\
\hline False passage & 0.9 & - & - & 0.4 \\
\hline Urinary tract infection & - & 1 & - & 1.7 \\
\hline Pyelonephritis & - & - & - & 1.0 \\
\hline \multicolumn{5}{|l|}{ Major Complications, $\%$} \\
\hline Perforation & 4.6 & 1.7 & 1 & 0 \\
\hline Stricture & 1.4 & 0.7 & 0.5 & 0.4 \\
\hline Avulsion & 0.6 & 0 & 0 & 0 \\
\hline Urinoma & 0.6 & - & 0 & 0 \\
\hline Urosepsis & 0.3 & 0 & 0 & 0 \\
\hline
\end{tabular}


nable alternative to nephroureterectomy in select patients. Ureteroscopic treatment of higher-grade urothelial lesions is palliative, but can be employed for local control.

\section{REFERENCES AND RECOMENDED READINGS}

1. YOUSEM, D.M.; GATEWOOD, O.M.; GOLDMAN, S.M. y cols.: "Synchronous and metachronous transitional cell carcinoma of the urinary tract: Prevalence, incidence, and radiographic detection". Radiology, 167: 613, 1988.

2. BAGLEY, D.H.; HUFFMAN, J.L.; LYON, E.S.: "Flexible ureteropyeloscopy: Diagnosis and treatment in the upper urinary tract". J. Urol., 138: 280, 1987.

3. BAGLEY, D.H.; RIVAS, D.: "Upper urinary tract filling defects: Flexible ureteroscopic diagnosis". J. Urol., 143: 1196, 1990.

4. GRASSO, M.; FRAIMAN, M.; LEVINE, M.: "Ureteropyeloscopic diagnosis and treatment of upper urinary tract urothelial malignancies". Urology, 54: 240, 1999.

5. CHEN, G.L.; BAGLEY, D.H.: "Ureteroscopic Surgery for Upper Tract Transitional-CellCarcinoma: Complications and Management". J. Endourology, 15: 399, 2001

6. GRASSO, M.: "Flexible FiberopticUreteropyeloscopy". Smith, A.D.; Lingeman, J.E.; Bagley, D.H.; Preminger, G.M.; Clayman, R.V.; Badlani, G.H.; Jordan, G.H.; Kavoussi, L.V.; Segura, J.W.; eds. Smith's Textbook of Endourology. Vol 1. St Louis, Mo: Quality Medical Publishing, págs. 443-54, 1996.

7. JOHNSON, G.B.; PORTELA, D.; GRASSO, M.: “Advanced Ureteroscopy: Wireless and Sheathless". J. Endourology, 20: 552, 2006.

8. BAGLEY, D.; KULP, D.A.; BIBBO, M.: "Ureteroscopic biopsy optimized by cytopathologic techniques". J. Urol., 151: 387, 1994.

9. MARTINEZ-PINEIRO, J.A.; GARCIA MATRES, M.J.; MARTINEZ-PINEIRO, L.: "Endourological treatment of upper tract urothelial carcinomas: Analysis of a series of 59 tumors". J. Urol., 156: 377, 1996.

10. ELLIOTT, D.S.; SEGURA, J.W.; LIGHTNER, D. y cols.: "Is nephroureterectomy necessary in all cases of upper tract transitional cell carcinoma? Long-term results of conservative endourologic management of upper tract transitional cell carcinoma in individuals with a normal contralateral kidney". Urology, 58: 174, 2001.

11. KEELEY, F.X.; BIBBO, M.; BAGLEY, D.H.: "Ureteroscopic treatment and surveillance of upper urinary tract transitional cell carcinoma”. J. Urol., 157: 1560, 1997.

12. KEELEY, F.X.; KULP, D.A.; BIBBO, M. y cols.: "Diagnostic accuracy of ureteroscopic biopsy in upper tract transitional cell carcinoma”. J. Urol., 157: 33, 1997.

13. MURPHY, D.M.; ZINCKE, H.; FURLOW, W.L.: "Primary grade 1 transitional cell carcinoma of the renal pelvis and ureter". J. Urol., 123: 629, 1980.

14. IBORRA, I.; SOLSONA, J.; CASANOVA, J. y cols.: "Conservative elective treatment of upper urinary tract tumors: A multivariate analysis of prognostic factors for recurence and progression”. J. Urol., 169: 82, 2003.

15. VEST, S.A.: "Conservative surgery in certain benign tumors of the ureter". J. Urol., 53: 97, 1945.

16. STREEM, S.B.; PONTES, E.J.: "Percuaneous management of upper urinary tract transitional cell carcinoma". J. Urol., 135: 773, 1986.

17. SMITH, A.D.; ORIHUELA, E.; CROWLEY, A.R.: "Percutaneous management of renal pelvic tumors: A treatment option in select cases". J. Urol., 137: 852, 1987.

18. HUFFMAN, J.L.; BAGLEY, D.H.; LYON, E.S. y cols.: "Endoscopic diagnosis and treatment of upper-tract urothelial tumors. A preliminary report". Cancer, 55: $1422,1985$.

19. SCHMELLER, N.T.; HOFSTETTER, A.G.: "Laser treatment of ureteral tumors". J. Urol., 141: 840, 1989.

20. JOHNSON, D.E.: "Use of the holmium: YAG (Ho: YAG) laser for treatment of superficial bladder carcinoma”. Laser Surg. Med., 14: 213, 1994.

21. PLANCKE, H.R.F.; STRIJBOS, W.E.M.; DELAERE, K.P.J.: "Percutaneous endoscopic treatment of urothelialtumours of the renal pelvis". BJU Int., 75: 736, 1995.

22. POTTER, S.R.; CHOW, G.K.; JARRETT, T.W.: "Percutaneous endoscopic management of urothelial tumors of the renal pelvis". Urology, 58: 457, 2001.

23. HUANG, A.; LOW, R.K.; DEVERE, W.R.: "Nephrostomy tract tumor seeding following percutaneous manipulation of a ureteral carcinoma". J. Urol., 153: 1041, 1995.

24. PATEL, A.; SOONAWALLA, P.; SHEPHERD, S.F. y cols.: "Long-term outcome after percutaneous treatment of transitional cell carcinoma of the renal pelvis". J. Urol., 155: 868, 1996.

25. PATEL, A.; FUCHS, G.J.: "New techniques for the administration of topical adjuvant therapy after endoscopic ablation of upper urinary tract transitional cell carcinoma”. J. Urol., 159: 71, 1998.

26. THALMANN, G.N.; MARKWALDER, R.; WALTER, B. y cols.: "Long-term experience with bacillus Calmette-Guerin therapy of upper urinary tract transitional cell carcinoma in patients not eligible for surgery". J. Urol., 168: 1381, 2002.

27. KEEELEY, F.X.; BAGLEY, D.H.: “AdjuventMitomycin C Following Endoscopic Treatment Of Upper Urinary Tract Transitional Cell Carcinaoma”. J. Urol., 158: 2074, 1997.

28. SCHNAPP, D.S.; WEISS, G.H.; SMITH, A.D.: "Fever following intracavitary bacillus Calmette-Guerin therapy for upper tract transitional cell carcinoma". J. Urol., 156: 386, 1996.

29. BELLMAN, G.C.; SWEETSER, P.; SMITH, A.D.: "Complications of intracavitary bacillus Calmette-Guerin after percutaneous resection of upper tract transitional cell carcinoma". J. Urol., 151: 13, 1994.

30. CHEN, G.L.; BAGLEY, D.H.: "Ureteroscopicmanagement of upper urinary tract transitional cell carcinoma in patients with contralateral kidneys". J. Urol., 164: 1173, 2000.

31. RAZDAN, S.; JOHANNES, J.; VOX, M. y cols.: "Current practice patterns in the urologic management of upper tract transitiona; ce; carcinoma". J. Endourol., 19: 366, 2005.

32. SODERDAHL, D.W.; FABRIZIO, M.D.; RAHMAN, N.U. y cols.: "Endoscopic treatment of upper tract transitional cell carcinoma". Urol. Oncol., 223: 114, 2005.

33. JOHNSON, G.B.; FRAIMAN, M., GRASSO, M.: "Broadening experience with the retrograde endoscopic management of upper urinary tract urothelial malignancies". BJU Int., 95: 110, 2005. 